\title{
LA FISCALIDAD INTERNACIONAL Y LOS CONVENIOS PARA EVITAR LA DOBLE IMPOSICIÓN
}

\author{
AN INTERNATIONAL TAXATION AND AGREEMENTS TO AVOID \\ DOUBLE IMPOSITION
}

\author{
Adolfo Santa Cruz Miranda* \\ Docente Auxiliar de la Facultad de Ciencias Contables \\ Universidad Nacional Mayor de San Marcos-UNMSM / Lima-Perú \\ [Recepción: Setiembre de 2014/ Conformidad: Octubre 2014]
}

\section{RESUMEN}

El Perú, desarrolla desde hace alrededor de 20 años una política macroeconómica de apertura a los capitales internacionales, a la exportación de productos primarios y a la promoción de bienes sujetos a un proceso productivo que les genere un valor agregado exportable y competitivo en el mercado mundial. En ese contexto, constituye una "política de Estado", la suscripción de "tratados internacionales", que nos permiten complementar y consensuar nuestras políticas macroeconómicas con otros países, así como el estudio, evaluación y resolución de sus efectos tributarios, en la búsqueda de seguridad jurídica a la inversión extranjera y la competitividad de nuestra producción con valor agregado, mirando al mundo como objetivo. El trabajo analiza y explica las causas que generan la doble imposición jurídica internacional, morigerada en sus efectos tributarios por los correctivos establecidos en los CDI. Debido a ello, nos abocamos al análisis y comentarios de la finalidad y alcances de los Convenios Marco para evitar la doble imposición, que nuestro país ha utilizado como prototipos para adecuarlos, negociarlos y finalmente, suscribir convenios con terceros países. El Convenio Marco más utilizado por nuestro país es el Modelo OCDE (Organización para la Cooperación y el Desarrollo Económico), organismo dependiente del denominado "Grupo 20", donde se encuentran los principales países del mundo. El segundo Convenio Marco es el desarrollado por las Naciones Unidas. Ambos "Convenios Marco" tienen alcances distintos, que también analizamos, en tanto utilizan criterios diferenciados para determinar el país al que corresponderá gravar la renta.

\section{Palabras clave:}

Barreras arancelarias; tratados internacionales; tributos; politicas macroeconómicas, doble imposición jurídica internacional; inversión.

\begin{abstract}
The Peru, develops from about 20 years ago macroeconomic policy of opening up to international capital, the export of primary products and the promotion of goods subject to a production process that will generate an exportable and competitive value added in the world market. In this context, is a "state policy" subscription "international agreements" that allow us to complement our macroeconomic policies and agree with other countries, and the study, assessment and resolution of their tax effects, in the search for legal certainty to foreign investment and competitiveness of our value-added production, looking at the world as a target.

This work analyzes and explains the causes of international juridical double taxation, which originated in their tax effects corrective established in CDI. Because of this, we apply ourselves the analysis and comments on the purpose and scope of the framework agreements to avoid double taxation, our country has been used as prototypes to suit, negotiate and eventually sign agreements with third countries. The Framework Convention's used by our country is the OECD Model (Organization for Economic Cooperation and Development), an agency of the so-called "Group 20", where the main countries in wich the world is found. The second framework convention is that developed by the United Nations. Both "framework agreements" have different scopes, they also analyzed, while using different criteria to determine the country to which it falls to tax income.
\end{abstract}

\section{Keywords:}

Tariff barriers; international treaties; taxes; macroeconomic policies, international juridical double taxation; investment.

* Contador Público Colegiado - UNMSM. Email:adolfosantacruzm@terra.com.pe 


\section{INTRODUCCIÓN}

Desde finales del siglo pasado, el hecho económico más relevante a nivel mundial, ha sido la apertura de mercados y la globalización de las economías, lo que significó una paulatina desaparición de las barreras arancelarias y para-arancelarias y, el establecimiento en los países con economías abiertas (caso del Perú) de una interdependencia de reglas externas, en lo económico.

En lo político, este hecho coincidió con la caída del Muro de Berlín y la desaparición de la Unión Soviética, ahora compuesta por Rusia y otros distintos países, los que incluso se encuentran fuera de su esfera de influencia política, caso actual de Ucrania, país en conflicto que busca su incorporación a la Unión Europea.

Actualmente, lo que sucede en la política económica mundial repercute con fuerza en los denominados países emergentes, en particular en países latinoamericanos, entre los cuales se incluye al Perú.

La globalización ha generado la búsqueda de la productividad, acompañada de una asignación eficiente de recursos de capital - generalmente de grupos multinacionales -, mano de obra y recursos logísticos. Actualmente, la movilidad del capital es más fluida que la de los bienes, habiéndose reemplazado a nivel internacional el antiguo modelo de importación y exportación (import-export) de bienes y servicios, por un modelo ampliado a la inversión internacional y a la mano de obra calificada.

A pesar de los avances de la economía y el comercio mundial, aún subsisten las barreras fiscales. Ello es así, porque la soberanía de los Estados óius imperium - genera diferencias producidas por la autonomía jurisdiccional en la legislación tributaria, principalmente la del Impuesto a la Renta. Esta autonomía jurisdiccional la determina cada Estado, con criterios combinados de domicilio o territorial (fuente), solo subsanables en sus operaciones mediante Acuerdos Internacionales denominados Convenios para evitar la doble imposición, a través de los cuales los países pierden jurisdicción pero ganan en trans- parencia fiscal para beneficio de los contribuyentes de cada estado signatario.

En este contexto, ha surgido la denominada fiscalidad o tributación internacional, como respuesta a la competencia entre los países para ofrecer las mejores ventajas en incentivos y beneficios tributarios y la provisión de seguridad jurídica a la inversión de capitales foráneos. Cabe señalar que, también se ha generado una competencia fiscal perjudicial o "nociva" efectuada por países y territorios de baja o nula imposición, conocidos como "paraísos fiscales". Los países han intentado e intentan contrarrestar la competencia fiscal perjudicial, principalmente mediante barreras legislativas. A nivel internacional la Organización para la Cooperación y el Desarrollo Económico (OCDE por sus siglas en inglés), organismo técnico-jurídico dependiente del G- $20^{1}$ ha impuesto una "lista negra" de paraísos fiscales, de la que solo pueden ser retirados aquellos países que asuman el compromiso de adoptar normas de transparencia fiscal e intercambio de información en materia fiscal.

La presente investigación ha sido desarrollada con la intención de incentivar al estudio de la fiscalidad internacional, en particular y principalmente de los "Convenios para evitar la doble imposición" (CDI), como tarea - ya no mediata, sino inmediata -, atendiendo a que nuestro país tiene actualmente una de las economías más abiertas a nivel latinoamericano y un régimen macroeconómico mantenido invariable a través de sucesivos gobiernos durante los últimos 20 años y, lo que es más importante, con un consenso interno para continuar desarrollando y profundizando las mencionadas políticas, complementándolas con políticas sociales para beneficio de los que más lo requieren.

\section{MARCO TEÓRICO}

\section{REGULACIÓN DE LOS TRATADOS internacionales en el Perú}

El Artículo No 51 de la Constitución Política del Perú, establece que "la Constitución prevalece sobre toda norma legal; la Ley, sobre las normas de inferior jerarquía, y así sucesivamente...”. 
Basada en dicho marco general, el Artículo No 55 de la Constitución, establece que "los Tratados ${ }^{2}$ celebrados por el Estado y en vigor forman parte del derecho nacional”. Por otro lado, el Artículo No 56, señala al respecto que "los tratados deben ser aprobados por el Congreso antes de ser ratificados por el Presidente de la República. Tal es el caso de los tratados, que crean, modifican o suprimen tributos; los que exigen modificación o derogación de alguna Ley y los que requieren medidas legislativas para su ejecución". Para su aprobación por el Congreso y su conversión en Ley de la República, los tratados internacionales deben contar primero con un documento definitivo y consensuado, surgido en una previa negociación efectuada por los Estados partícipes. Así, el Congreso de la República tiene la potestad constitucional de aprobar o desaprobar el tratado, pero no de modificarlo como puede suceder con una Ley nacional. Cuando un tratado entra en ejecución, se convierte en una norma de carácter obligatorio para los Estados partícipes. No existe la menor posibilidad de que un Estado pretenda desconocer sus alcances porque ello significaría alterar la estabilidad del ordenamiento jurídico internacional y el Estado incurriría en una responsabilidad internacional.

Para la aplicación de un tratado internacional se usa el aforismo legal "pacta sunt servanda". Esto quiere decir, que lo pactado se cumple. Dicho principio es la norma que sustenta la obligatoriedad de los tratados internacionales.

Las diferencias determinadas entre lo que señala un Tratado y una ley nacional, se resuelven aplicando lo dispuesto en los tratados internacionales. Aun cuando la norma constitucional no señala expresamente cómo se soluciona un conflicto entre un Tratado y una Ley nacional, el Artículo No 57 establece que, "la denuncia de los tratados es potestad del Presidente de la República, con cargo a dar cuenta al Congreso". En el caso de los Tratados Internacionales sujetos a aprobación por el Congreso, la denuncia requerirá aprobación previa de este. Es así que, un conflicto irreparable entre un Tratado y una Ley interna, se resuelve aplicando el procedimiento de denuncia dispuesto por el Artículo No 27 de la Con- vención de Viena, de 23 de Mayo de 1969 - suscrita y ratificada por el Perú -. En resumen, un país solo podrá intervenir en oposición a tratados vigentes a través del procedimiento de denuncia que dispone el Derecho Internacional.

\section{LA DOBLE IMPOSICIÓN INTERNACIONAL}

La doble imposición puede ser nacional o internacional. El presente estudio se relaciona con el análisis de la doble imposición internacional, porque son estados los que exigen la pretensión económica del tributo y el fenómeno de la imposición surge como una manifestación de la soberanía estatal.

Así las cosas, la doble imposición internacional también denominada jurídica -, se produce cuando un mismo supuesto gravable determina el nacimiento de más de una obligación tributaria en dos diferentes Estados, por el mismo o análogo concepto y en un mismo período de tiempo, el cual debe corresponder a un ejercicio económico y fiscal. Ello significa, gravar más de una vez y por el mismo concepto en dos diferentes Estados, lo que solo se soluciona implementando políticas tributarias unilaterales dispuestas por los Estados, o, de manera definitiva, por la vía de la suscripción de un convenio para evitar la doble imposición.

Guillermo Cabanellas en su Diccionario Jurídico Elemental (2002:34), ha señalado que jurídicamente la analogía significa la interpretación de una norma fundándose en el espíritu de un ordenamiento positivo o en los principios generales del Derecho.

\section{CAUSAS DE LA DOBLE IMPOSICIÓN INTERNACIONAL}

El doble gravamen surge por la utilización en dos Estados autónomos de diferentes criterios de imposición. Un primer Estado gravará a la persona natural o jurídica bajo el criterio de residencia o domicilio. Este criterio determina señalar que los contribuyentes domiciliados en un Estado se encuentran gravados por sus rentas de fuente mundial, vale decir, por las rentas que obtienen en el país y las rentas que obtienen en el exterior. Así las cosas, el otro Estado aplicará 
para sus operaciones gravadas el criterio territorial o de fuente, según el cual los sujetos no domiciliados estarán gravados por las rentas que obtengan en dicho Estado. Es decir, se gravarán las rentas obtenidas por los sujetos no domiciliados en dicho país, tomando en consideración su innegable autonomía jurisdiccional.

\section{SOLUCIONES UNILATERALES DISPUESTAS PORLA LEGISLACIÓN DE LOS PAÍSES PARA EVITAR LA DOBLE IMPOSICIÓN}

En el supuesto de que no se cuente con un CDI, los países han incorporado en sus legislaciones medidas unilaterales para evitar la doble imposición sobre las rentas que sus residentes obtienen en el exterior, las mismas que se gravan como rentas de fuente extranjera. Es así que, la Ley del Impuesto a la Renta del Perú establece que los contribuyentes domiciliados $^{3}$ tributan sobre sus rentas de fuente mundial, vale decir las obtenidas en el país y en el exterior (de fuente extranjera).

Con la misma potestad jurídica a la que nos referimos en el párrafo anterior, el Estado donde el contribuyente ha obtenido la renta, también la grava basándose en un criterio territorial o de fuente. Así se genera la doble tributación internacional, que - en una economía de mercado abierta - resulta perjudicial para el sujeto gravado, pero también para el comercio y servicios internacionales entre países.

Cuando no se cuenta con un CDI, en nuestro país se aplica como solución unilateral para evitar la doble tributación, el método de "imputación ordinaria”. Mediante este método, el Estado peruano permite que un residente deduzca la cuota del Impuesto pagada en el extranjero como crédito contra su propio Impuesto, hasta el límite del que le hubiera correspondido pagar en el Perú. Es decir, se acepta el crédito del exterior o el Impuesto que le tocaría gravar al país, el que sea menor, aplicando el procedimiento conocido como "tasa media del contribuyente".

\section{LOS CONVENIOS ENTRE PAÍSES PARA EVITAR LA DOBLE IMPOSICIÓN}

Los Convenios para evitar la doble imposición son tratados internacionales suscritos entre dos Estados como fruto de una decisión surgida en atención a razones tributarias ${ }^{4} y$, en su caso, no tributarios ${ }^{5}$. Los CDI también se suscriben con el propósito de prevenir el fraude fiscal, por lo que, incorporan "Acuerdos de información" entre las administraciones tributarias de los países signatarios, propugnando de esta manera una mejor fiscalización de los contribuyentes - personas naturales o jurídicas - domiciliadas para los impuestos a los que se refiere el Convenio.

Para que se cumpla con el objetivo esencial de evitar la doble imposición, los CDI constituyen un medio para distribuir la potestad tributaria entre los países signatarios. En sus efectos prácticos, los CDI modifican o suspenden la aplicación de tributos internos, en particular del Impuesto a la Renta, en alguno de los países signatarios. Como consecuencia de la suscripción de un CDI los países renuncian a su potestad tributaria en la determinación del Impuesto a la Renta interno; aplicando, en lo que corresponda, las disposiciones del Convenio Internacional. Los CDI no crean impuestos, solo califican los hechos imponibles de los países para efectos de repartir la potestad tributaria.

Existen a nivel mundial dos "Modelos Marco" de CDI. El primero de ellos es el elaborado por la Organización para la Cooperación y el Desarrollo Económico (OCDE por sus siglas en inglés), organismo dependiente del denominado Grupo 20, que conforman los países más importantes del mundo, y al que el Perú aspira pertenecer al igual que México y Chile, países de Latinoamérica que ya son miembros plenos. En base al Modelo Marco de la OCDE, el Perú ha suscrito los siguientes CDI:

\footnotetext{
3 Peruanos y extranjeros con residencia habitual en el Perú por más de 183 días en un período cualquiera de 12 meses y personas jurídicas constituidas en el Perú.

4 Evitar la doble imposición del Impuesto a la Renta y, en su caso, la del Impuesto al Patrimonio. No se aplican para el Impuesto General a las Ventas por tratarse de un impuesto que grava, exclusivamente, las operaciones internas de un país.

5 Surgen por la voluntad de atraer al país capitales internacionales brindándoles seguridad jurídica que lo haga más atractivo como destino de las inversiones
}

182/ QVIPURAMAYOC | Vol. 22(42) 2014 


\section{CDI suscritos por el Perú Modelo Marco OCDE}

\author{
Países \\ República de Chile \\ República de Canadá \\ República de Brasil \\ Estados Unidos Mexicanos \\ República de Corea \\ Confederación Suiza \\ República de Portugal
}

Vigencia

01.ENE.2004

01.ENE.2004

01.ENE. 2010

01.ENE.2015

01.ENE.2015

01.ENE.2015

Este Modelo Marco -actualizado anualmente-, es aplicable principalmente por los países exportadores de capitales o países emergentes con pretensiones de serlo.

El segundo Modelo Marco es el elaborado por las Naciones Unidas. En base a este modelo Marco, el Perú ha suscrito el Régimen para evitar la doble imposición con los países miembros de la Comunidad Andina de Naciones. El comentado CDI, se encuentra vigente, según lo dispuesto por la Decisión No 578, desde el 01.ENE.2005.

El Modelo Naciones Unidas - a diferencia del Modelo OCDE - ha sido elaborado tomando en consideración los requerimientos macroeconómicos para países importadores de capitales.

\section{FINALIDAD Y ALCANCES DEL CONVENIO MARCO MODELO OCDE}

- Este CDI constituye un medio para eliminar o reducir la imposición del Impuesto a la Renta en el Estado de la fuente; vale decir en el Estado donde se genera la renta. Es así que, el Modelo asigna una imposición exclusiva para el estado de residencia del sujeto gravado.

- El CDI se aplica a quienes residen en alguno de los Estados signatarios. La residencia será determinada de acuerdo con la legislación interna de cada Estado signatario - generalmente 183 días calendarios en un período cualquiera de 12 meses para los sujetos no domiciliados personas

naturales -. Para las personas jurídicas se entiende como residencia a su sede de dirección efectiva ${ }^{6}$.

- Para el tratamiento de las denominadas rentas pasivas - regalías, intereses y dividendos - el Convenio Marco establece un régimen de tributación compartida. Ello significa que en adición al gravamen en el país de la residencia, el país de la fuente, también puede gravar la renta, pero, en este último caso, sujeta a límites expresamente establecidos en el Convenio.

- El Convenio Marco Modelo OCDE busca evitar el abuso con fines de elusión tributaria, cuando se genera su aprovechamiento indebido, conocido como "treaty shopping". Dicho aprovechamiento indebido persigue incorporar en las ventajas del CDI a un residente de un país distinto al de los países signatarios. Ej.: Empresa domiciliada en un país signatario cuyos accionistas no son sujetos domiciliados en ese país. Tampoco domicilian en el otro país signatario del CDI.

- El presente Convenio Marco incluye a los Impuestos a la Renta y, de considerarse así en los respectivos CDI individuales, al Impuesto al Patrimonio. Cualquier modificación posterior al Impuesto a la Renta efectuada por cualquiera de los países signatarios en su legislación interna no afectará la vigencia del Convenio.

RÉGIMEN PARA EVITAR LA DOBLE IMPOSICIÓN Y PREVENIR LA EVASIÓN FISCAL

\section{- CONVENIO MARCO MODELO NACIONES} UNIDAS

\section{Decisión No 578 - Comunidad Andina de Naciones - Publicada en la Gaceta Oficial de la CAN}

- El Convenio Marco Modelo Naciones Unidas es aplicable a las personas - naturales y jurídicas domiciliadas en cualquiera de los países miembros de la Comunidad Andina de Naciones.

- El Convenio se aplica a los Impuestos a la Renta de Perú, Colombia, Bolivia y Ecuador. También es

6 De acuerdo con la Ley del Impuesto a la Renta del Perú, las personas jurídicas son consideradas residentes en atención a su lugar de constitución, según lo disponga la Ley General de Sociedades (LGS). 
aplicable a las modificaciones que se introduzcan a dichos impuestos y cualquier otro Impuesto, que en razón de sus respectivas hipótesis de incidencia, fuera esencial y económicamente análogo al que establezcan los países miembros a futuro.

- El término persona incluye a las personas naturales y jurídicas (empresas) domiciliadas en cada uno de los países de la CAN.

- Una empresa domicilia en el país que señala su instrumento de constitución ${ }^{7}$. Si no lo expresa, la empresa domicilia donde se encuentra su administración efectiva ${ }^{8}$.

- Independientemente del domicilio de las personas naturales o jurídicas residentes en cada uno de los países miembros de la CAN, las rentas que obtengan solo serán gravadas por el país miembro en que tales rentas tengan su fuente productora, salvo casos de excepción previstos por la Decisión No 578. Los demás países miembros donde residan las persona naturales o jurídicas, deberán considerar a las rentas como exoneradas para efectos del Impuesto a la Renta9.

\section{CONCLUSIONES}

1. La fiscalidad o tributación internacional ha surgido como respuesta a la competencia de los países para ofrecer ventajas tributarias a los inversionistas, así como la provisión de seguridad jurídica en un contexto económico globalizado.

2. La autonomía jurisdiccional de la legislación tributaria de los Estados ha generado el fenómeno conocido como doble tributación internacional referida al Impuesto a la Renta que les corresponderá pagar a los contribuyentes - personas naturales o jurídicas - cuando efectúan operaciones en dos diferentes Estados.

3. El desarrollo por cada estado de criterios combinados de tributación para gravar a los contribuyentes por su domicilio o residencia o por el lugar donde han obtenido la renta (criterio objetivo o fuente), ha contribuido a generar la suscripción de acuerdos internacionales denominados Convenios para evitar la doble imposición. Mediante dichos CDI, los países deben estar dispuestos a perder jurisdicción en el propósito de ganar en transparencia fiscal para beneficio de los contribuyentes de cada Estado signatario.

4. Los Artículos Nos. 55 al 57 de la Constitución Política que nos rige, al referirse a la aprobación de los Tratados Internacionales, entre los cuales se encuentran los Convenios para evitar la doble imposición, no han establecido taxativamente las reglas para su procedimiento de aprobación y ratificación por el Congreso de la República; así como, el tratamiento jurídico dispuesto por el Derecho Internacional ante el surgimiento de un conflicto entre una Ley del Perú y un Tratado Internacional.

5. El doble gravamen internacional surge como consecuencia de la autonomía jurisdiccional para gravar la renta, cuando un mismo supuesto gravable determina el nacimiento de más de una obligación tributaria en dos diferentes Estados, por el mismo o análogo concepto y en un mismo período de tiempo. El primer Estado gravará la renta bajo el criterio de residencia o domicilio, mientras que el segundo la gravará siguiendo el criterio de fuente o territorial.

6. En el propósito de limitar o reducir los efectos de la doble imposición internacional, los Estados, como es el caso de nuestro país, han establecido medidas unilaterales. Dichas "medidas" señalan que el Impuesto a la Renta pagado en el exterior constituye un crédito contra el Impuesto a la Renta total del contribuyente, hasta el límite del Impuesto interno que le correspondería pagar. Estas medidas unilaterales solo son compensables conla suscripción de Convenios entre países para evitar la doble imposición (CDI). Los CDI constituyen un medio para distribuir la potestad tributaria entre los países signatarios de los mismos, en el

7 Así también lo establece la legislación del Impuesto a la Renta del Perú.

8 El Modelo OCDE señala que para el caso de las personas jurídicas, el criterio básico es el de "Sede de dirección efectiva".

9 Criterio distinto al que rige para el Convenio Marco Modelo OCDE y para la legislación peruana del Impuesto a la Renta, que aplican como criterio principal para gravar la renta el de residencia, vale decir que gravan la renta obtenida en el país y la que se obtiene en el exterior (conocido como de fuente mundial).

184/ QVIPURAMAYOC | Vol. 22(42) 2014 
propósito de que la renta solo sea gravada en un país signatario, o que, bajo un concepto de tributación compartida, para determinadas operaciones sea distribuida equitativamente entre ambos.

7. El Convenio Marco Modelo de la OCDE utilizado mayormente por nuestro país y el Convenio Marco Modelo Naciones Unidas utilizado por los países miembros de la Comunidad Andina de Naciones, entre los que se incluye al Perú, desde distintas perspectivas, apuntan al propósito esencial de evitar la doble imposición jurídica internacional. Así las cosas, deben seguir siendo utilizados para nuestras operaciones, con terceros países, profundizando y mejorando sus alcances, para lo cual será necesario corregir lo que requiera ser corregido en las legislaciones internas de cada país signatario.

\section{RECOMENDACIONES}

1. Se recomienda establecer mediante Ley de la República los procedimientos de aprobación de los Tratados Internacionales por el Poder Ejecutivo y su ratificación por el Congreso de la República según corresponda; así como, los procedimientos de denuncia establecidos por el Derecho Internacional cuando surja un conflicto inevitable entre una Ley nacional y un Tratado internacional.

2. Profundizar el estudio de las medidas unilaterales aplicables en el Perú para evitar la doble imposición internacional, con países con los cuales no se hayan suscrito Convenios para evitar la doble imposición.
3. Profundizar y mejorar los alcances de los Convenios para evitar la doble imposición que le corresponda suscribir al Perú, corrigiendo lo que deba ser corregido en las normas jurídicas internas de nuestro país.

\section{REFERENCIAS BIBLIOGRÁFICAS}

1. BRENKER, Thomas M. y SHERMAN N. Richard (2005) "Alivio de la doble tributación Internacional (las bases)”. Revista de Tributación Internacional WGCL.

2. Organization for Economic Cooperation and Development (OCDE) (2013) Comittee on Fiscal Affairs, Model Tax Conventions on Income on a Capital.

3. Estudios de Derecho Tributario Internacional (2006) Los Convenios de doble Imposición, Instituto Colombiano de Derecho Tributario, Legis Editores S.A.

4. Organización para la Cooperación y el Desarrollo Económico (OCDE) (2012) Modelo de Convenio tributario sobre la Renta y sobre el Patrimonio.

5. Naciones Unidas (2002) "Convenio Modelo de las Naciones Unidas sobre la doble tributación”.

6. Constitución Política del Perú 1993 - Congreso de la República - Edición 2013. 